\title{
SUJEIÇÃO, SUBJETIVAÇÃO E MIGRAÇÃO: RECONFIGURAÇÕES DA GOVERNAMENTALIDADE BIOPOLÍTICA*
}

\author{
Cesar Candiotto** \\ https://orcid.org/0000-0002-7172-4618 \\ ccandiotto@gmail.com
}

RESUMO $O$ artigo estuda, em um primeiro momento, os processos de sujeição e subjetivação nos trabalhos de Michel Foucault e sua relação com a dupla dimensão, moral e material, da governamentalidade. Se em sua dimensão moral a produção de sujeições tem como contraponto os processos éticos de subjetivação, já em sua dimensão material predomina o governo biopolítico do meio vital no qual populações são reguladas e sujeitadas em detrimento das possibilidades de subjetivação. A ênfase do governo biopolitico é especialmente observável entre as populações deslocadas em busca de sobrevivência. Em um segundo momento evoca-se, para além de Foucault, uma modalidade de população problematizada como objeto de recorrente normalização nos últimos decênios, constituida pelos migrantes de sobrevivência. O estudo percorre os traços do governo biopolítico dessa população, especialmente as reconfigurações dos processos de sujeição que a regulam. Conclui-se que ela apresenta poucas possibilidades de empreender processos de subjetivação como resistência às formas de sujeição operadas pela governamentalidade biopolítica.

* Artigo submetido em 05/09/2019. Aprovado em 16/10/2019. O presente artigo foi realizado com apoio do Conselho Nacional de Desenvolvimento Científico e Tecnológico (CNPq), Chamada Universal 28/2018, Processo: 422565/2018-0, intitulado: "As novas fronteiras da biopolítica contemporânea", e como resultado parcial da Bolsa de Produtividade em Pesquisa, do CNPq (2018-2021), Processo: 307257/2018-5, intitulado: "Migrantes pobres e indivíduos improdutivos: novas formas de governo da vida e gestão dos ilegalismos na biopolítica contemporânea" (2019-2022), ambos executados na Pontifícia Universidade Católica do Paraná (PUCPR).

** Pontifícia Universidade Católica do Paraná (PUCPR). Curitiba, PR, Brasil.

KRITERION, Belo Horizonte, nº 146, Ago./2020, p. 319-338 
Palavras-chave Governamentalidade, Biopolitica, Sujeição, Subjetivação, Migração, Michel Foucault.

ABSTRACT At first, the article studies the processes of subjection and subjectivation in the works of Michel Foucault and their relationship with the double dimension, moral and material, of governmentality. If in its moral dimension the production of subjections has as its counterpoint the ethical processes of subjectivation, in its material dimension what predominates, in turn, is the biopolitical government of the vital means in which populations are regulated and subjected to the detriment of the possibilities of the subjectivation. The emphasis of the biopolitical government is especially noticeable among displaced populations seeking survival. In a second moment, besides Foucault, a modality of population that has been problematized as object of recurrent normalization in the last decades, made up by survival migrants, is evoked. The study goes through the traits of the biopolitical government of that population, especially the reconfigurations of the subjection processes that regulate it. We conclude that it presents few possibilities to undertake subjectivation processes as resistance to the forms of subjection operated by the biopolitical governmentality.

Keywords Governmentality, Biopolitics, Subjection, Subjectivation, Migration, Michel Foucault.

\section{Introdução}

Na série de conferências de maio de 1973, na PUC-Rio, A verdade e as formas jurídicas, Foucault apropria-se do pensamento de Nietzsche a fim de indicar que o conhecimento científico não advém de um desejo natural do saber, mas é marcado por um começo de pouca glória, pela faísca resultante do choque entre duas espadas (Foucault, 1994). No mesmo espírito deste momento inicial de sua analítica do poder, ele postula que as ciências humanas não chegam a seu estágio atual pelo progresso neutro do conhecimento sobre o homem e o indivíduo e, sim, pela "poeira" ou pelo sangue seco derramado em inúmeras batalhas entre saberes dominantes e "saberes sujeitados". ${ }^{1}$ Considerando que

1 A referência aos saberes sujeitados foi desenvolvida na aula de 7 de janeiro de 1976, no curso Em defesa da sociedade, e diz respeito aos "blocos de saberes históricos que estavam presentes e disfarçados no interior dos conjuntos funcionais e sistemáticos e que a crítica pôde fazer aparecer [...] pelos meios da erudição" (Foucault, 1999, p. 11). Mas trata-se, também, de uma "série de saberes denominados como não conceituais, 
o objeto das ciências humanas é o homem, entendido ao mesmo tempo como sujeito de conhecimento e objeto de saber, uma das perguntas fundamentais que alimenta a genealogia do poder dos anos setenta é a seguinte: quem somos nós hoje? Mais precisamente: o que fizeram de nós para que nos reconhecêssemos somente no interior de processos de sujeição revestidos de um matiz científico, os quais, por sua vez, não deixam de ser a sedimentação legitimada de relações nada cristalinas entre poder e saber?

Por sua vez, em Vigiar e punir, lemos que as ciências humanas e sociais, desde o século XIX, não teriam sido possíveis sem uma multiplicidade de objetivações no interior de práticas que envolvem distribuições espaciais e controles temporais. Nas "instituições de sequestro"² que se desdobram da invenção do panóptico moderno, os indivíduos são fabricados como sujeitos sujeitados por técnicas de disciplinamento dos corpos (mecanismos de premiações e punições) que demandam reconhecimento e consentimento, desembocando na constituição de uma vontade obediente em relação à norma. Já nos dispositivos de regulação da vida, estudados no último capítulo do livro de 1976, História da sexualidade I: A vontade de saber, e nas primeiras lições do curso de 1978, Segurança, território, população, os corpos são tomados

como saberes insuficientemente elaborados: saberes ingênuos, saberes hierarquicamente inferiores, saberes abaixo do nível do conhecimento ou da cientificidade requeridos" (Ibid., p. 12). A imbricação entre os conteúdos históricos do saber meticuloso, exato, técnico, erudito que foram sepultados pela erudição e o saber singular e local das pessoas - que não é o do senso comum - deixados em repouso ou mantidos sob tutela (o do psiquiatrizado, o do enfermeiro, etc., normalmente esquecidos pelo poder médico) é o ponto no qual reside a força essencial da crítica foucaultiana do discurso desde o início dos anos sessenta. No saber erudito sepultado nas unidades teóricas e no saber das pessoas desqualificado hierarquicamente é que encontramos o "saber histórico das lutas" e sobre o qual a genealogia tenta restabelecer a memória dos combates, revogando a tirania dos discursos unitários e totalizantes. A genealogia define-se, neste contexto, como o "acoplamento dos saberes eruditos e das memórias locais, acoplamento que permite a constituição de um saber histórico das lutas e a utilização deste saber nas táticas atuais" (Ibid., p. 13). Trata-se, na estratégia genealógica, de fazer intervir "saberes locais, descontínuos, desqualificados, não legitimados contra a instância teórica unitária que pretenderia filtrá-los, hierarquizá-los, ordená-los em nome de um conhecimento verdadeiro, em nome dos direitos de uma ciência que seria possuída por alguns" (Ibid., p. 13).

2 Em 1973, no curso A sociedade punitiva, a expressão designa diversas instituições, como fábricas, hospitais e prisões, nas quais impera uma "espécie de autoridade arbitrária que se apodera de algo, a retira da livre circulação e a mantém fixa em um certo ponto, durante um certo tempo, até uma decisão do tribunal" (Foucault, 2013, p. 214). Estas instituições funcionam de maneira adjacente aos aparelhos de produção, de transmissão do saber e de repressão, como um "suplemento de poder". Não são "aparelhos de Estado", embora operem como se fossem "pequenos Estados", já que necessitam, para poder funcionar, da polícia e do exército. Estes estabelecimentos não pertencem ao Estado, mas não funcionam sem ele; e, inversamente, são "multiplicadores de poder no interior de uma sociedade na qual a estrutura estatal permanece a condição de funcionamento dessas instituições" (Ibid., p. 215). Com exceção da prisão, que faz parte dos aparelhos de Estado, as demais instituições funcionam mediante uma microfísica do poder pela repartição dos indivíduos nos diversos aparelhos sociais. Foucault faz uma análise concentrada dos aparelhos repressivos do Estado e sua relação com estas instituições de sequestro cujo efeito é a fabricação do indivíduo pela norma. Portanto, uma perspectiva diferente daquela de Althusser, que se concentra na relação entre sujeito e ideologia pelo estudo dos Aparelhos Ideológicos do Estado (AIE) (Cf. Althusser, 2011, pp. 263-306). 
em amplos conjuntos definidos por seus traços biológicos ou por condições diferenciais em um meio vital e social específico.

Desta maneira, o indivíduo moderno é, segundo Foucault, o efeito de um processo de sujeição no âmbito da normalização disciplinar - que torna a multiplicidade dos corpos marcados pela vigilância e punição e objetivados por saberes com pretensão de se tornarem ciências. Mas sua vida é também objetivada por poderes (que conjugam disciplinamento e dispositivos securitários) e saberes (tais como a economia política, a estatística, a geografia humana, a psicologia comportamental) que o produzem como parte de uma "população"3 constituída biologicamente (pela sua relação com a saúde, com a origem genética, com a ascendência racial) ou economicamente (pela relação com a escassez, com a fome, com a necessidade de deslocamento). ${ }^{4}$

Um processo de sujeição realiza-se quando um indivíduo se reconhece na identidade que se desdobra das relações entre saber e poder estabelecidas no interior de uma prática social na qual ele se encontra concernido. Assim, alguém se identifica como indivíduo criminoso na relação entre tecnologias disciplinares e saberes sobre a criminalidade que dele exigem não somente a confissão da autoria do ato, mas também seu suplemento, que é a admissibilidade verbal de que é um criminoso. É insuficiente a confissão do crime; é ainda necessário reconhecer-se nele. A relação microfísica entre saber e poder cujo efeito é o autorreconhecimento como "sujeito" criminoso torna-o, no mesmo gesto, sujeitado. Ele é levado a reconhecer-se pelos padrões de normalização que o situam entre um ou outro lado de uma fronteira socialmente estabelecida ou de práticas divisórias que o cindem por dentro. A genealogia, portanto, parte do presente ao problematizar "quem somos nós?" e pergunta-se sobre o que "fizeram de nós" nas diferentes camadas históricas do passado.

No caso de um indivíduo objetivado como parte de uma população, os processos de sujeição envolvem a produção de identidades coletivas

3 Foucault estabelece uma correlação entre a arqueologia do nascimento do homem moderno em As palavras e as coisas e a genealogia do nascimento da população, em Segurança, território, população: "Daí uma consequência: é que a temática do homem, através das ciências humanas que o analisam como ser vivente, indivíduo trabalhador e sujeito falante, deve-se compreendê-la pela emergência da população como correlativa de poder e como objeto de saber. O homem, tal como foi pensado, definido a partir das ciências ditas humanas do século XIX e tal como foi refletido no humanismo do século XIX, este homem é, finalmente, somente uma figura da população. (Foucault, 2004, p. 81).

4 No último capítulo de História da sexualidade I: $A$ vontade de saber, bem como na última lição do curso Em defesa da sociedade, ambos de 1976, é problematizado o surgimento da população por um viés mais próximo do saber da biologia, seja seus desdobramentos no darwinismo social do fim do século XIX, seja nas políticas totalitárias da primeira metade do século XX. Entretanto, desde 1978, em Segurança, território, população, quando as relações de poder são reconfiguradas pelo conceito de governamentalidade, o saber privilegiado é o da economia política. Assim, a população pode designar tanto traços biológicos inerentes à vida de uma população tomada enquanto espécie, quanto sua relação com os meios relacionados com a materialidade da existência. 
biopolíticas. Assim, noções da filosofia política tradicional, como a de "povo", somente são possíveis no âmbito de uma operação histórica de contínuas sujeições pelas quais outras vidas ou maneiras de viver delas foram afastadas. A definição de "povo" sempre entranha a produção de "populações" que não se encaixam nessa identidade política. Qualquer tentativa de designação de povo é a naturalização no nível supostamente político de uma relação de poder que é de ordem biopolítica. As estratégias de análise arqueológica e genealógica buscam esgarçar esse reconhecimento e autorreconhecimento naturalizado pelas relações entre saber e poder nas práticas sociais e discursivas. Elas evidenciam que as unidades políticas tradicionais - neste caso, a de povo - têm como subsolo a fixação e o reconhecimento dos indivíduos aquém ou além de uma fronteira. Como bem observa Judith Butler: "De um modo ou de outro, a ação discursiva que visa a estabelecer 'o povo', de uma ou de outra maneira, é uma exigência de reconhecimento de fronteira, queira se trate da fronteira de uma nação ou da fronteira de uma categoria de pessoas reputadas como 'reconhecíveis' enquanto povo" (Butler, 2016, p. 12), dando a entender que há outras categorias que são excluídas deste reconhecimento.

\section{Desdobramentos morais e biopolíticos da governamentalidade}

Além de estabelecer o diagnóstico de quem somos nós ao evidenciar que seu reconhecimento não designa necessariamente uma pertença igualitária e democrática, a genealogia aponta para a identidade biopolítica desse nós, apreensível somente pela constituição de uma fronteira discursiva que delimita comunidades raciais e linguísticas, filiações políticas ou nacionalidades. Por conseguinte, um primeiro momento dessa genealogia consiste em apontar os processos de sujeição que produzem o indivíduo moderno pelas coerções da norma ou fabricam as populações pela regulação dos fluxos e fronteiras. Dupla sujeição, portanto, que diagnostica quem "sou” e quem somos "nós", ou ainda, quem "sou" a partir de um determinado "nós".

Realizado o diagnóstico, impõe-se como segundo momento a questão: que podemos fazer de nós mesmos a partir daquilo que fizeram de nós? Formulado de outra maneira: diante das relações entre saber e poder e seus processos de sujeição, observáveis nas tecnologias disciplinares e na regulação biopolítica, seria possível frear, dobrar ou, até mesmo, liberar-se das sujeições consentidas e das evidências sedimentadas?

Uma primeira resposta a respeito consiste em sustentar que não conseguimos nos libertar totalmente dessas sujeições, assim como é dificilmente imaginável que haja um fora em relação às estratégias de poder-saber resultantes da 
constituição de uma singularidade totalmente imune à sua captura. Se não logramos sair das relações entre poder e saber ou das identificações em relação às quais nós mesmos nos sentimos partícipes; se inexiste uma vida que não seja o efeito da inscrição de técnicas de poder-saber, convicção esta que descarta a existência de uma potência vital que se insurgiria de fora contra aquelas relações de poder, então o que podemos fazer de nós envolve tomar conhecimento de como estas técnicas foram formadas e impuseram-se sobre outras técnicas ou saberes sujeitados, as quais podem ser ativadas como condição de um desvio possível.

É insuficiente pensar a constituição do sujeito moderno somente pelo diagnóstico dos processos de sujeição evidenciados na inscrição de seus corpos e na produção de sua "alma" nos limites das tecnologias disciplinares. De igual maneira, seria incorrer em parcialidade postular a constituição da população apenas pela sua produção como vida coletiva, infiltrada ${ }^{5}$ pela relação entre técnicas regulamentadoras e saberes populacionais, como os da biologia, da demografia, da estatística e da geografia humana. Se for verdade que a reconfiguração das disciplinas no interior da biopolítica permite a análise de conjuntos populacionais em meios abertos ou semiabertos, o diagnóstico destas técnicas de poder não vislumbra, contudo, a possibilidade da constituição de um sujeito que não seja o sujeito da normação ou o sujeito da normalização. ${ }^{6}$

5 Se o objeto população é frequentemente designado como conjunto vivente, por sua vez, a vida é raramente separada das técnicas que a marcam e a definem, sejam elas disciplinares, biopolíticas ou governamentais. Mesmo o discurso da biologia ou da botânica, que supostamente estudaria a vida fora da história, somente é possível historicamente no interior de uma ordem do discurso determinada, de uma disciplina que opera no interior de uma comunidade científica que situa certos saberes como verdadeiros e, outros, como falsos. Pode ocorrer que, em virtude da relação entre saber e poder de uma época, seja concebido como verdadeiro um erro disciplinado, e como falsa uma verdade indisciplinada (Cf. Foucault, 1971). Portanto, a noção de vida, para uma ciência possível, possui uma neutralidade somente aparente, posto que as relações que a delimitam e a recortam são indissociáveis da luta em torno do poder e da verdade. A vida e os prazeres, no terreno da sexualidade, não podem ser pensados como potências que escapam totalmente às técnicas de poder que incidem sobre o sexo. Diante da tecnologia biopolítica que se impõe sobre a regulação da vida e da sexualidade, o que se deve contrapor, como resistência, não é uma vida ou uma forma de prazer dissociada de qualquer tecnologia, mas, pelo contrário, outra técnica cujo efeito seria outra forma de vida e outra modalidade de prazer.

6 A diferença entre disciplinas e mecanismos de segurança no que concerne à sua relação com a norma é realizada no curso de 1978, Segurança, território, população. Nas disciplinas, parte-se da norma, e é o adestramento fixado por ela que permite estabelecer a separação entre o normal e o anormal. Nas técnicas de segurança, pelo contrário, são identificadas primeiramente diversas curvas de normalidade, sendo que a normalização consiste em "fazer atuar, umas em relação às outras, essas diferentes distribuições de normalidade, de maneira que as mais desfavoráveis sejam reconduzidas àquelas mais favoráveis" (Foucault, 2013 , p. 65). Começa-se, neste caso, do normal, o qual se serve de distribuições mais normais que outras e são estas distribuições que servem de norma. Assim, "a norma é um jogo no interior das normalidades diferenciais. O normal vem por primeiro, sendo a norma dele deduzida". Conclui Foucault: "direi que não se trata de uma normação, mas antes, no sentido restrito, enfim, de uma normalização" (Ibid., p. 65. Grifos nossos). 
O curso de 1978, Segurança, território, população, é decisivo a esse respeito. Nele é evidenciado que os mecanismos de segurança que surgem na passagem do século XVII para o século XVIII já não se referem aos mesmos objetos. Até essa época, esses mecanismos visam à segurança do território e, por meio dele, a segurança do príncipe que o governa. Mas o crescimento das cidades exige um deslocamento dos mecanismos de segurança devido ao problema da circulação: das mercadorias, dos focos de doença e da morte. Os mecanismos de segurança voltam-se para o controle da circulação da população e daqueles que a governam. A circulação no interior das cidades impõe-se como objeto de governo diante de seu escopo anterior que é a solidez do território. Não se trata mais de evitar que as coisas mudem - que a segurança do território garanta a manutenção do príncipe no poder -, mas de deixar que as circulações ocorram permanentemente, ainda que controladas, discriminadas entre as boas e as ruins, de maneira que os perigos que lhe são inerentes sejam eliminados. Menos soberania do território e mais governo da circulação de uma população, portanto.

A emergência da circulação da população como objeto de mecanismos de segurança não somente reconfigura o que, em termos de filosofia política, entende-se por "povo". Ela também introduz, no interior do território, a noção de "meio" a ser governado. Ela é responsável pelo deslocamento do par territóriosoberania para o par população-governo. Depreende-se que a série "segurançapopulação-governo" (Foucault, 2004, p. 91) parece ser a mais adequada, aos olhos de Foucault, para intitular o curso de 1978. Sem a intenção de adentrarme nos desdobramentos desta série, interessa-me a introdução da noção de governamentalidade, da aula de 1 de fevereiro, e como ela desempenha um papel crucial para a relação entre sujeição e subjetivação. Trata-se de saber se ela possibilita ir além da análise daquilo que fizeram de nós na normação disciplinar e na normalização biopolítica, ao permitir responder também à questão sobre o que podemos fazer de nós mesmos.

Com efeito, a governamentalidade tem sido concebida como a técnica responsável pelo deslocamento da analítica do poder para a genealogia das relações entre sujeito e verdade. Ela teria possibilitado a ultrapassagem dos "impasses" da analítica do poder, como o da relação microfísica entre poder e resistências. ${ }^{7}$ Estas leituras estão alinhadas ao volume de pesquisas desenvolvido nos anos 1980, nas quais o governo dos outros é reconfigurado como dobra do governo de si mesmo. Elas acertam quando indicam que essa dupla dimensão do 
governo permite estabelecer o fio condutor entre os trabalhos dos anos setenta e aqueles da primeira metade dos anos oitenta. Elas estão focadas em um dos desdobramentos dessa noção, que é seu sentido moral, entendido amplamente como a arte de governar as condutas envolvendo a condução de um grupo de indivíduos, a relação entre indivíduos ou, ainda, a condução de si mesmo. ${ }^{8}$

Elas normalmente deixam de lado um segundo desdobramento, que é sua conotação material. E, no entanto, é esta última que permite reconfigurar a biopolítica no interior da governamentalidade, bem como especificar uma modalidade de população designada pela sua referência "ao deslocamento no espaço, ao movimento que se refere à subsistência material, à alimentação [...]" (Foucault, 2004, p. 126). Se há uma biopolítica circunscrita pela análise do dispositivo da sexualidade, se há outra que pode ser delimitada pela ênfase no racismo estatal (e, em certo sentido, estas duas biopolíticas, embora distintas, cruzam-se entre si), não seria forçoso acenar para uma terceira modalidade de biopolítica em 1978, associada ao deslocamento de uma população em busca de subsistência material. A esta terceira modalidade, podemos designá-la como governamentalidade biopolítica.

Desenvolverei duas hipóteses de trabalho a seu respeito: a primeira, consiste em tentar demonstrar que o desdobramento material da governamentalidade é distinto, mas não necessariamente separado de seu desdobramento moral, permitindo o estabelecimento de vínculos entre o governo da circulação de uma população em busca de subsistência e os processos de subjetivação empreendidos em torno dessa população. A segunda concerne à exemplificação desse vínculo em uma modalidade de população cuja regulação e constituição tem sido objetivada com frequência nas últimas décadas, formada pelos migrantes de sobrevivência ${ }^{9}$ em razão da crise econômica ou da violência das guerras e genocídios em seu meio vital e social de origem. E, contudo, essa população não fez parte das genealogias de Foucault, talvez porque as práticas

8 No âmbito desse último desdobramento, em 1978 ainda não é estabelecida a diferença entre a tentativa governamental de determinar as ações e/ou comportamentos dos indivíduos, diante dos quais estes tentam agir não se deixando determinar por aquela tentativa de condução de conduta mediante o governo de si mesmos. O governo das condutas que se concretiza nos códigos morais e prescritivos é sempre uma possibilidade inerente a qualquer cultura, embora não tanto entre os gregos antigos. Diante destes códigos, a ética, composta, dentre outros elementos, por formas de subjetivação que envolvem a relação do indivíduo consigo mesmo, não procura exatamente negá-los, mas desviar-se deles, constituir no indivíduo outra relação marcada por certo distanciamento ou sua relativa aceitação segundo critérios de razoabilidade, e não de obediência automática da vontade. Daí a diferença fundamental: "uma coisa é, com efeito, uma regra de conduta; outra, a conduta que se pode medir a essa regra” (Foucault, 1984, p. 37).

9 Alexander Betts (2010, p. 366) denomina os deslocamentos involuntários como migrações de sobrevivência. Como parte daqueles que são obrigados a deixar os seus países de origem estão os refugiados. Contudo, muitos migrantes de sobrevivência não são considerados refugiados, ainda que todos os refugiados sejam migrantes de sobrevivência. 
governamentais que a elevaram a um objeto maior a ser pensado pela política não se mostravam ainda tão evidentes. ${ }^{10}$

\section{Sujeição biopolítica e possibilidade de processos de subjetivação}

Explanarei a primeira destas hipóteses, no intuito de analisar como a implicação entre a conotação moral e a vertente material da governamentalidade biopolítica produz efeitos de sujeição na constituição de identidades individuais e coletivas, mas também processos de subjetivação em relação a estas sujeições identitárias mediante a introdução de desvios, transgressões e resistências. E, para isso, acenarei brevemente à maneira como é apresentada a governamentalidade no Ocidente pela emergência do poder pastoral cristão em Segurança, território, população.

A figura da relação entre pastor e rebanho esboçada neste curso tem sido situada frequentemente no âmbito da condução moral dos indivíduos, enfocada na ambiência da condução das almas na prática da direção de consciência monástica. É pela instauração de um tipo de poder baseado na relação entre pastor e rebanho que podemos identificar os primeiros traços de uma condução moral, mas também material, de uma população em deslocamento em busca de subsistência em um meio vital. Nesse "meio" aberto de circulação de uma pastagem a outra e de um campo a outro é que o pastoreio pode ser designado metaforicamente como o governo biopolítico de todos, mas também como o governo moral de cada um.

Porcerto, o pastor conduz o rebanho em seu sentido coletivo e indiferenciado; mas também pode efetivar a condução individual e moral de cada um, sempre que ele for em busca da ovelha perdida, especialmente quando ela se "desgarra" do rebanho. Essa dupla condução do poder pastoral inaugura no Ocidente um curioso processo de sujeição: de um lado, uma sujeição individualizada, a fim de que o indivíduo não se desgarre do fluxo, da circulação do rebanho, de maneira que, quando ele se desviar, deverá ser reconduzido a seu meio no qual é induzida a normalização de sua conduta. E, de outro, uma sujeição coletiva, posto que, quando o pastor vai em busca da ovelha perdida, está convencido de que as demais não irão dispersar-se. E estas, por sua vez, não estão totalmente

10 Não obstante, veja-se a importante entrevista de 17 de agosto de 1979, a H. Uno, no Japão, intitulada "O problema dos refugiados é o presságio da grande migração do século XXI" (Foucault, 2001a, pp. 798-800). Foucault é entrevistado a respeito das grandes migrações forçadas do sudeste da Ásia, que chegaram a mais de 80.000 pessoas, principalmente do Vietnã e do Camboja. Ainda que esta entrevista tenha ocorrido no mesmo ano do curso Nascimento da biopolítica, ele não faz qualquer referência à relação entre "a grande migração do século XXI" e a governamentalidade biopolítica. 
seguras que chegarão a um bom pasto ou que se deslocarão adequadamente sem a condução do pastor.

Esta metáfora utilizada por Foucault pode ser considerada o índice da indissociabilidade entre o desdobramento biopolítico e o desdobramento moral da governamentalidade ocidental: no caso de uma população, não se trata somente de regular seu meio vital de circulação enquanto coletividade, mas também de empreender a condução de condutas de cada um, de modo que os desvios sejam evitados ou integrados no interior daquela regulação. O governo material da subsistência do conjunto de determinadas vidas é indissociável do governo moral dos comportamentos e da vontade.

Mas no governo biopolítico de uma população deslocada em busca de condições materiais de sobrevivência não são identificados somente processos de sujeição, individuais e populacionais, mas também processos de subjetivação. Nesse sentido, algo interessante da metáfora da relação entre pastor e rebanho é que no próprio nascimento da genealogia do governo existe sempre a virtualidade de circular de outra maneira, transgredir certas fronteiras, romper com formas de ser conduzido que identificam a população a um rebanho; e o governo biopolítico, a uma espécie de pastoreio que cuida sob a condição da sujeição.

Podem, portanto, ser chamados processos de subjetivação tanto as resistências individuais e interindividuais empreendidas diante de uma moral do rebanho, como também as contracondutas de uma população que não se deixa governar por uma regulação biopolítica determinada. Assim como as sujeições podem ser individualizadas ou coletivamente produzidas, de igual maneira os processos de subjetivação podem ser individuais ou populacionais. As tentativas de dobra de uma relação de governo por parte de uma população; a recusa em ser conduzido de uma certa maneira e por determinados pastores ou governantes; o desgarramento de uma autoimagem que o sujeito elabora de si mesmo diante de uma certa condução de sua conduta são diferentes possibilidades de processos de subjetivação individuais e coletivos.

A noção de subjetivação é tratada pela primeira vez no curso de 1978 , ainda que de maneira esporádica. Em uma passagem do manuscrito deste curso aparece, entre algumas palavras ilegíveis, uma questão pertinente para a compreensão dos trabalhos de Foucault: "como ser sujeito sem ser sujeitado?" (Foucault, 2004, p. 237). As tentativas de resposta a essa questão podem ser encontradas implícita ou explicitamente em textos como $O$ sujeito e o poder, o último volume dos Dits et écrits, os cursos no Collège de France entre 1980 e 1984 e a "Introdução" aos volumes II e III da História da sexualidade. O conjunto dessas passagens permite-me formular a questão de outra maneira: como se 
constituir como sujeito diante dos processos de sujeição? Ou ainda, como os processos de subjetivação apresentam-se como uma saída permanente, embora jamais acabada, diante das formas de sujeição, individuais e populacionais?

Um processo de subjetivação procura tomar distância da fixação identitária resultante do contato dos indivíduos com as malhas do poder ou da normalização de uma população pela regulação biopolítica. Ele envolve, em primeiro lugar, a tentativa de saída de identidades estabelecidas pela relação entre saber e poder e naturalizadas pelo sujeito; supõe deixar de pensar o que se pensa para poder pensar de outra maneira; impõe prescindir das sendas que levam a um lugar seguro para empreender o descaminho daquele que se aventura a caminhar. Apresenta-se como a tentativa de deixar de viver da maneira como se vive em busca da constituição de outro estilo de existência. Finalmente, e este parece ser o ápice de um processo de subjetivação, ele exige a não conformidade servil aos dispositivos disciplinares e biopolíticos nos quais vivemos.

Como a expressão aponta, trata-se sempre de um processo permanente de resistência e criação, de transformação do sujeito na relação que ele tem consigo mesmo, com os outros e com o mundo, com os códigos morais e mecanismos biopolíticos de pertencimento em relação aos quais ele é levado a identificar-se. O processo de subjetivação não demanda forçosamente o rompimento total com estes códigos e mecanismos, mas uma relação diferente com eles, no sentido de colocá-los em suspeição ou suspensão; de torcê-los em vista da criação de outras relações que ponham em xeque identidades constituídas, bem como a normalização dos papéis sociais que se utilizam de práticas temerárias de inclusão e exclusão.

Geralmente nos compreendemos no interior dos processos de normalização das condutas produzidas nas práticas sociais e científicas. A subjetivação pressupõe, pelo contrário, a conversão do olhar que procura desfazer-se das objetivações produtoras de identidades populacionais negativas. Diversos são os agentes que procuram dizer quem somos e, assim, tutelar nossa vida e nosso ser pelo reconhecimento de uma identidade sujeitada. É o que ocorre, por exemplo, com boa parte das atuais políticas de migração de alguns países desenvolvidos, que mais se assemelham a uma polícia migratória quando exigem respostas a interrogatórios sem fim das populações migrantes em busca de subsistência, de maneira que o migrante é levado a objetivar-se como um hóspede hostil.

No curso de 1982, A hermenêutica do sujeito, Foucault ressalta que não há resistência possível ao poder político que não passe por uma nova relação do sujeito consigo mesmo (Foucault, 2001b). De maneira análoga, não se pode empreender um processo de subjetivação diante da regulação biopolítica de uma população se, ao mesmo tempo, os indivíduos que a compõem não 
estabeleçam uma relação diferencial em relação a si mesmos. As formas de resistências populacionais exercidas na imanência da regulação biopolítica são inseparáveis das resistências individuais que operam na verticalidade de nós mesmos.

É mister uma relação ética do sujeito consigo mesmo para que ele tome distância da fixação das identidades individuais e populacionais, sejam as deduzidas de uma suposta interioridade pré-constituída, sejam as resultantes de um saber-poder pretensamente verdadeiro. Do ponto de vista dos processos de subjetivação, não se trata de substituir um "si mesmo" por um "novo eu", mas de permanecer na relação entre um e outro. Não vivemos sem identidades, mas não podemos nos fixar àquelas que foram produzidas em razão de um processo de sujeição ou de uma regulação biopolítica. Pelo contrário, convém valorizar as identidades coletivas e políticas produzidas pelas lutas comuns, plurais e transversais das populações das quais fazemos parte, assim como participar das lutas de outras populações objetivadas negativamente pela governamentalidade biopolítica. Todavia, as identidades coletivas e políticas constituídas em torno dessas lutas comuns não podem saturar-se, sob o risco de obliterar a expressão de nossas maneiras de ser e viver.

A subjetivação é uma relação entre quem estamos deixando de ser e quem ainda não somos. Quando permanecem estrategicamente nesta posição lacunar do "entre", os sujeitos constituídos no âmbito das resistências às disciplinas e à biopolítica não são totalmente capturados pela moral civil e pelas inscrições de seus corpos nas distribuições espaciais onde normalmente se espera que devam estar, ou pelos controles temporais que deles exigem o bom adestramento e a autovigilância de suas atividades. Os processos de subjetivação desviam-se dos padrões comportamentais que são esperados dos sujeitos e é nesse sentido que eles não são automaticamente responsivos às tentativas de condução das condutas. Eles situam-se, pois, em um espaço agonístico, supõem um embate que envolve colocar-se e posicionar-se rumo a uma atitude-limite, a uma alteração que pode levar a diferentes formas de saída heterotópicas.

\section{Processos de sujeição e população migrante}

Depois da incursão que priorizou a leitura peculiar dos elementos conceituais propostos por Foucault a respeito dos processos de sujeição e subjetivação, desloco-me para minha segunda hipótese. Ela procura testar o alcance de suas pistas de pesquisa para o caso das populações que migram em busca de sobrevivência material. Com efeito, os processos de sujeição a que essa população tem sido submetida nas últimas décadas autorizam-nos 
a reconhecê-la como um novo objeto de regulação da governamentalidade biopolítica.

Nos últimos decênios, deslocados pobres e politicamente vulneráveis em busca de socorro veem-se submetidos a novos processos de regulação e sujeição nos países onde pretendem ser acolhidos ou, ao menos, residir por algum tempo. Com frequência, a população dos migrantes de sobrevivência está associada às figuras da ilegalidade, da clandestinidade e da imoralidade, reconfigurando a objetivação do indivíduo perigoso à Nação ou à comunidade. Essa associação entre a objetivação moralizante e biopolítica tem como uma de suas raízes a crise desencadeada no mundo do trabalho em razão da hipervalorização da circulação célere do capital material e imaterial. Assim, os países desenvolvidos deslocam suas empresas e indústrias para os países pobres - muitos deles ex-colônias - para lá receberem subsídios governamentais, economizarem com os direitos trabalhistas e gastarem menos com a eliminação de resíduos poluentes. Mas, em contrapartida, impõem enormes dificuldades para a acolhida de populações de migrantes miseráveis desses países que batem às sua portas, sob a alegação de que oneram a seguridade social e provocam uma colonização invertida.

Desde alguns anos, quando os nacionalismos renascem na Europa, nos Estados Unidos e em outras partes do mundo, procura-se deslegitimar o direito a migrar como um direito humano. ${ }^{11}$ Jean-Louis Harouel, autor do livro Les droits de l'homme contre le peuple, considera, por exemplo, que a migração oriunda da África e do Oriente Médio em direção à União Europeia, especialmente à França, não se apresenta como uma migração de trabalhadores, mas como uma "migração de colonização". Segundo alega, o interesse dos ex-colonizados jamais é somar-se à composição da nação para onde se dirigem, mas valer-se de sua seguridade social com agrupamentos familiares extensos, dando ensejo a uma espécie de "contrassociedade", sem qualquer renúncia a seu estilo de vida ou esforço de integração aos valores do país de acolhida (Cf. Harouel, 2016, p. 203).

Entretanto, o escopo da integração, como seria uma migração aceitável pelo autor, é praticamente sinônimo de sujeição populacional e individual, de renúncia aos valores que se tem e aceitação inquestionável dos mecanismos de normação disciplinar e normalização da vida destas populações. Sempre que

11 No artigo 13, inciso 1, da Declaração Universal dos Direitos Humanos, afirma-se que "Toda pessoa tem o direito de deixar qualquer país, inclusive o próprio, e a este regressar” (ONU, 2013, p. 652). Já no artigo 14 , inciso 1, assegura-se que "Toda pessoa, vítima de perseguição, tem o direito de procurar e de gozar asilo em outros países” (ONU, 2013, p. 652). 
são obrigadas a deixar seus países é porque algum motivo as impede de neles se reconhecerem como um nós, como um povo. A migração de sobrevivência é um dos efeitos do sofrimento permanente e intolerável diante de uma maneira de viver sujeitada pelo autoritarismo político e/ou pela miserabilidade econômica. É muito difícil a constituição de um mundo comum e de uma vida qualificada ou digna de ser vivida sempre que faltarem as condições básicas de sobrevivência material. ${ }^{12}$ A luta pela subsistência é imposta pela própria realidade de abandono e vulnerabilização da vida, em boa parte devido à nova razão neoliberal do mundo que avalia todas as relações humanas pela racionalidade da globalização dos bens, da rentabilidade e do lucro (Cf. Dardot; Laval, 2010), indissociável do ímpeto autoritário de criminalização das manifestações políticas e lutas pelos direitos sociais.

As migrações de sobrevivência envolvem experiências de dessubjetivação e novas sujeições. Dessubjetivação, porque os indivíduos já não se reconhecem na comunidade na qual construíram seu pertencimento, não conseguem mais agir livremente ou dizer o que pensam. Deixam de se sentir protegidos para colocar em prática uma maneira de viver que projetaram e escolheram para si mesmos. Não vêm garantidas as condições socioeconômicas mínimas para que possam continuar a viver e, até mesmo, subsistir. Trata-se de uma saída de si mesmos e de seu mundo que é forçada e, portanto, não impelida por processos de subjetivação. Estamos diante do enfrentamento de situações nas quais a única possibilidade é lutar por continuar a sobreviver, deslocando-se de um espaço inóspito a outro incerto.

Guerras civis, ditaduras, neocolonialismos e novos autoritarismos são máquinas produtoras de populações, ou seja, de vidas apreensíveis somente por sua condição biopolítica, as quais, deslocando-se à procura de sobrevivência

12 Ao contrário de Arendt, para a qual a redução das lutas à luta pela sobrevivência poderia minar a luta pelo direito de ter direitos na esfera da pluralidade política, Judith Butler considera que é impossível empreender lutas por direitos políticos sem que o corpo seja bem alimentado, possa repousar e descansar, enfim, sem que as necessidades em torno da esfera da vida biológica sejam satisfeitas. A perspectiva arendtiana encontrada em $A$ vida do espírito e inspirada em uma passagem de A defesa de Sócrates consiste em afirmar que o "viver em si" não tem um valor intrínseco. Somente o "bem-viver" (eudaimonia) torna a vida digna de ser vivida. Butler considera que essa perspectiva não é válida para nosso tempo, ou, talvez, nunca tenha sido. Segundo ela, Arendt separa a vida do corpo da vida do espírito e, por isso, prefere em análises, como Escritos judeus, que o povo escolhido opte antes por uma morte digna a insistir na mera sobrevivência a qualquer preço. Butler entende que a esfera pública depende da privada, assim como o ato verbal público depende do corpo. O corpo é político. O privado não é o contrário do público, como parece afirmar Arendt em A condição humana, mas faz parte de sua própria definição. Muitas vezes o "escondimento" da desigualdade no privado (especialmente das mulheres) é condição para o "reconhecimento" na esfera pública. Significa que a suposta pluralidade, como condição política e excelsa do ser humano, pode ser exercida às custas da desigualdade no âmbito privado. Butler, por sua vez, sustenta que a aparição pública depende da igualdade no privado. A crítica dessa dependência não reconhecida, do público em relação ao privado, fornece-lhe o ponto de partida de uma nova política do corpo (Butler, 2016, pp. 254-255). 
material, foram tornadas "meras vidas". ${ }^{13}$ Essas máquinas de desqualificação da vida, de animalização do humano poderiam também ser pensadas como máquinas de sujeição. Ser obrigado a deixar seu país envolve ver-se forçado a abandonar relações que foram construídas, processos de subjetivação que foram constituídos no decurso da existência. E, nesse sentido, os migrantes despossuídos veem-se sempre diante de um atravessamento fronteiriço geográfico (pelo mar, por terra) que é ao mesmo tempo antropológico, posto que novas fronteiras cruzam o interior de si mesmos, cindindo-os por dentro e objetivando-os como população exposta e vulnerável.

Trata-se de um atravessamento que demanda deixar para trás quem se era e como se vivia, diante do apelativo igualmente forçado da "integração" à terra e à cultura de um destino sempre temerário. $\mathrm{O}$ atravessamento que envolve o desenraizamento como condição da integração é uma sujeição sem fim. Nos países em que chegam, os migrantes são impelidos a esvaziar-se do que pensam, do que fazem e do que são, a fim de incorporar uma língua estranha e um estilo de viver muito diferente (Cf. Arendt, 2013, pp. 5-16). Inclusive nos processos migratórios menos dramáticos, não se concretiza a reciprocidade e o respeito mútuo das diferentes maneiras de viver, entre quem chega e quem recebe, como se poderia esperar em uma integração efetiva. Com frequência, os migrantes são impelidos a incorporar unilateralmente os valores do País que os "socorre" como condição preliminar para que sejam eventualmente "aceitos".

Como ressalta Benjamin Boudou:

A hospitalidade dificilmente é compatível com a igualdade. A relação entre acolhedores e acolhidos supõe o respeito das leis de quem acolhe, a gratidão por aquilo que deve ser vivido como um dom generoso e, eventualmente, a deferência para com os acolhidos. Ainda que o estrangeiro seja beneficiado por um estatuto honorífico, isso só vem mascarar a desigualdade constitutiva da relação (Boudou, 2017, pp. 177-178).

A acolhida dos migrantes de sobrevivência envolve quase sempre uma relação de desigualdade e, por isso, muito dificilmente ela pode ser pensada somente no horizonte de uma ética da hospitalidade. ${ }^{14}$ Desde o momento em

13 A noção de "mera vida" (das blosse Leben) encontra-se no ensaio Para uma crítica da violência (Zur Kritik der Gewalt), de Walter Benjamin (2013, p. 154), em referência a uma vida completamente despida de direitos.

14 A hospitalidade em relação aos migrantes de sobrevivência pode ser pensada a partir de sua dimensão ética, mas ela não pode ignorar a dimensão política. Ainda que a hospitalidade incondicional, como a encontramos em Derrida, possa ser um horizonte ético irrenunciável, ela é dificilmente realizável. Neste sentido -e, talvez, somente neste -, é preferível o realismo político ao idealismo moral. "Levar a hospitalidade a sério envolve [...] renunciar à ideia de uma ética da migração perfeitamente justa. Em vista da não-dominação é que ela adquire seu sentido. [...] trata-se de desfazer-se das ambições teóricas 'moralistas' para preferir um tratamento 'realista' da questão migratória. A hospitalidade deve, pois, ser considerada a partir das condições efetivas de acolhida" (Boudou, 2017, p. 218). 
que atravessam as fronteiras geográficas e passam a residir provisoriamente nos países de acolhida, os integrantes dessas populações precisam informar quem são, onde moram, com quem vivem, obrigando-se assim a enfrentar novas fronteiras. Um migrante que não adere às fixações e às disciplinas dos centros de detenção ou dos controles migratórios das grandes cidades torna-se um indivíduo perigoso, um mal a ser combatido.

$\mathrm{O}$ argumento dos críticos conservadores de que os migrantes não querem se integrar aos valores da democracia ocidental é, muitas vezes, rebatido pela própria operacionalidade dos Estados que os recebem. É a exclusividade do papel securitário do Estado que dificulta aos migrantes a criação de raízes e a constituição de relações com os autóctones ou nacionais. Como ocorre na Selva de Calais, na França, eles são obrigados a mudar-se constantemente de lugar para que não tenham contatos duradouros e criem familiaridades com a população local. Assemelham-se, pelo menos em sua forma, a um poder pastoral que regula um rebanho em permanente deslocamento, porém de maneira invertida: é considerado ovelha desgarrada aquele que tenta fixar-se e integrar-se a um lugar e a uma comunidade. $O$ único lugar em que a fixação é permitida é um não lugar, juridicamente indefinido, que é o campo de detenção. Trata-se de uma fixação sem qualquer integração ou pertencimento político. Neste caso, que é o da maioria solicitante de refúgio e acolhida atualmente, as condições insuportáveis do país de origem são duplicadas pela indefinição temporal e pelo limbo espacial do país de destino. Ei-los diante de um atravessamento incerto resultante de uma dupla exclusão. Na época contemporânea, esse não lugar marcado pela indefinição temporal é a mais nova heterotopia de uma comunidade política que produz seu negativo como maneira de restituir e resgatar um nacionalismo já erodido.

Quanto aos migrantes de sobrevivência, sem residência permanente, cidadania ou nacionalidade que vivem nas periferias das grandes cidades, são obrigados a trabalhar informalmente em troca de salários baixíssimos e sem seguridade social, como condição para que não sejam delatados aos controles migratórios por parte do patronado. Desta feita, ainda que os migrantes de sobrevivência sejam objetivados politicamente como indivíduos potencialmente perigosos, os processos de sujeição nos quais se encontram envolvidos têm uma função produtiva, pois aumentam a lucratividade dos donos dos meios de produção e reprodução do capital pela pressão sobre os salários.

Nesses processos, os migrantes "ilegais" são levados a participar de sua sujeição, a consentir com sua condição de clandestinos e sujeitados. As pré-condições exigidas para a integração por parte dos nacionalismos atuais colocam os migrantes em uma zona de indiscernibilidade. De um lado, eles 
não são partícipes de todos os direitos e condições de oportunidades de um cidadão; e, de outro, não são totalmente estrangeiros porque são incluídos na condição de ilegais. Em síntese, nas migrações de sobrevivência dois processos se complementam entre si: de um lado, a dessubjetivação forçada seguida da exclusão em um atravessamento sem fim; de outro, uma nova sujeição chamada de integração, porém operacionalizada pela inclusão do migrante periférico como ilegal e cujo efeito é a produção política da ilegalidade. ${ }^{15}$

\section{Considerações finais}

Transcorrido este percurso, convém perguntar: por que os migrantes de sobrevivência representam tanto perigo para os Estados desenvolvidos e para as comunidades políticas transnacionais? Considero que sua suposta periculosidade está associada, entre outras razões, às reconfigurações da governamentalidade biopolítica na época contemporânea. E sua principal característica consiste no acoplamento entre, de um lado, o disciplinamento e confinamento dos corpos em espaços fechados ou semiabertos e, de outro, a regulação de um meio vital aberto ou semiaberto sobre o qual é possível a introdução de técnicas cujas variáveis direcionam as vidas que lá se encontram a circular de uma determinada maneira e mediante comportamentos responsivos esperados.

Quando estes corpos e estas vidas são os das pessoas que migram massivamente em busca de sobrevivência, então a regularidade daquela circulação e a reconfiguração das formas de controle disciplinar são postas em crise. As inúmeras estratégias de desterritorialização e invisibilização de populações migrantes indesejáveis nas periferias das grandes metrópoles e nos campos de retenção fazem parte dos mecanismos de regulação biopolítica, ainda que, em alguns casos, essas populações sejam economicamente úteis. Pela mesma razão é que se torna necessária a estes governos a constituição de novos campos ou selvas delimitados por cercas elétricas ou muros, nos quais os migrantes objetivados como clandestinos deverão permanecer sob a forma do encarceramento indefinido e acompanhados de diversos processos de sujeição.

15 A estrutura do estado de exceção, apresentada por Agamben em outro registro metodológico, pode ajudar a entender a ausência de pertencimento político do migrante forçado ilegal e que, no entanto, tem como referência sua inclusão em um determinado território. Trata-se do que ele chama de "exclusão inclusiva", quando se exclui alguém, incluindo-o no próprio conjunto da exclusão. A produção da ilegalidade ou da exclusão inclusiva somente é realizada no interior de uma comunidade política. Não há como postular e reconhecer a exceção se ela não estiver incluída em uma estrutura política: "Se a exceção é a estrutura da soberania, a soberania não é, então, nem um conceito exclusivamente político, nem uma categoria exclusivamente jurídica, nem uma potência externa ao direito (Schmitt), nem a norma suprema do ordenamento jurídico (Kelsen): ela é a estrutura originária na qual o direito se refere à vida e a inclui em si através da própria suspensão" (Agamben, 2007, p. 35. Grifos nossos). 
A migração de sobrevivência é um problema a ser pensado porque ela se encontra no centro do diagnóstico político do presente em um momento histórico quando os corpos e as vidas dos migrantes são objetivados positiva ou negativamente, a depender de sua capacidade de fixação à dinâmica do fluxo do capital. Ela visibiliza os limites dos deslocamentos das grandes indústrias multinacionais em direção aos países pobres e miseráveis em busca de mão de obra barata, sem a constituição de uma infraestrutura que permita a esses trabalhadores permanecer em seus próprios países. Escancara o fato de que o bem-estar dos países centrais com seu modelo triunfante de globalização econômica e democracia liberal é pago com os malefícios que estes têm causado aos países periféricos. Atesta o escândalo de comunidades econômicas e políticas que, embora tenham ampliado as liberdades de mobilidade humana e os direitos para aqueles que nelas são cidadãos ou naturalizados, criaram novas e mais fechadas "zonas" de fronteiras, que se estendem dos campos de retenção à desnacionalização, passando pela inclusão dos migrantes via ilegalização ou a multiplicação e fragmentação dos sujeitos nela envolvidos. Por isso é que o atravessamento das fronteiras por parte destas populações em busca de sobrevivência é, paradoxalmente, acompanhado tanto da constituição de novas sujeições como também da hipocrisia de países cuja economia se desenvolve à custa da exploração destas mesmas populações no passado e no presente.

Postular a possibilidade de processos de subjetivação nos quais os agentes sejam a população migrante de sobrevivência é um desafio, posto que a indiscernibilidade na qual se encontram, ao serem lançados em um meio no qual estão nem inteiramente dentro nem totalmente fora de uma condição política, animaliza suas vidas e desqualifica suas existências. Como seria possível uma subjetivação não sujeitada a essas populações que se encontram compelidas continuamente a estratégias de separação não somente comunitárias, mas inclusive familiares? A decomposição e recomposição dos campos de retenção, as táticas de desarraigamento comunitário, a redução das singularidades a um número estatístico são tantas maneiras de dificultar, o máximo possível, uma relação satisfatória consigo mesmo, com os outros e com o mundo. Esse desarraigamento evidencia não somente o efeito mais nocivo do governo biopolítico dos migrantes de sobrevivência, como também diagnostica o declínio da política migratória e, por extensão, da própria política democrática, se a qualidade política de uma comunidade puder ser avaliada pela sua capacidade de abertura ou fechamento ao outro que pede socorro e acolhida. 


\section{Referências}

AGAMBEN, G. "Homo sacer: o poder soberano e a vida nua I". Trad. Henrique Burigo. $2^{\mathrm{a}}$. reimpressão. Belo Horizonte: Ed. UFMG, 2007.

ALTHUSSER, L. "Idéologie et appareils idéologiques d'État - notes pour une recherche”. In: ALTHUSSER, L. Sur la Reproduction. Paris: PUF, 2011. pp. 263-306.

ARENDT, H. "Nous autres réfugiés". Pouvoirs, 2013/1, n. 144, pp. 5-16. [Online]. DOI: 10.3917/pouv.144.0005. Disponível em: https://www.cairn.info/revue-pouvoirs2013-1-page-5.htm (Acessado em 10 de agosto de 2019).

BENJAMIN, W. "Para uma crítica da violência". In: Escritos sobre mito e linguagem (1915-1921). Org. J. M. Gagnebin. Trad. S. Kampff e E. Chaves. Ed. 34, 2013.

BETTS, A. "Survival Migration: A New Protection Framework". In: STILES, K.; LYON, A. J. (eds.). Global Governance: A Review of Multilateralism and International Organizations. 3. ed.: Brill, 2010. pp. 361-382.

BOUDOU, B. "Politiques de l'hospitalité". Paris: CNRS éditions, 2017.

BUTLER, J. "Peut-on mener une bonne dans une vie mauvaise?" In: Rassemblement: Pluralité, performativité et politique. Trad. C. Jacquet. Paris: Fayard, 2016.

DARDOT, P.; LAVAL, Ch. "La nouvelle raison du monde: essai sur la société néolibérale". Paris: La Découverte, 2010.

DEFERT, D. "Chronologie". In: Dits et écrits. Paris: Quarto/Gallimard, 2001. Vol. 1. DELEUZE, G. "Foucault”. Paris: Les Éditions de Minuit, 1986.

FOUCAULT, M. "L'ordre du discours. Leçon inaugurale au Collège de France prononcée le 2 décembre 1970". Paris : Gallimard, 1971.

. "La société punitive. Cours au Collège de France. 1972-1973". Paris: EHESS/ Gallimard/Seuil, 2013.

. "Em defesa da sociedade. Curso no Collège de France, 1975-1976”. São Paulo:

Martins Fontes, 1999.

."La vérité et les formes juridiques". In: Dits et écrits. Paris: Gallimard, 1994.

pp. 538-646. Vol. II.

. "Sécurité, territoire, population. Cours au Collège de France. 1977-1978".

Paris : Gallimard ; EHESSE ; Seuil, 2004.

. "O problema dos refugiados é o presságio da grande migração do século XXI".

In: Dits et écrits II. 1976-1988. Édition établie sous la direction de Daniel Defert et François Ewald avec la collaboration de Jacques Lagrange. Paris: Quarto/Gallimard, 2001a.

. "Histoire de la sexualité II : L'usage des plaisirs". Paris : Gallimard, 1984.

" "L'Herméneutique du sujet, cours au Collège de France (1981-1982)". Édition

établie sous la direction de François Ewald et Alessandro Fontana, par Fréderic Gros. Paris: Seuil/Gallimard, 2001b.

HAROUEL, J. L. "Les droits de l'homme contre le peuple". Paris: Declée de Brouwer, 2016.

LE BLANC, G.; BRUGÈRE, F. “La fin de l'hospitalité”. Paris: Flammarion, 2017. 
ORGANIZAÇÃO DAS NAÇÕES UNIDAS (ONU). "Declaração Universal dos Direitos Humanos das Nações Unidas (1948)". In: ISHAY, M. R. (org.) Direitos humanos: uma antologia. Principais escritos politicos, ensaios e documentos desde a Bíblia até o presente. Traduzido por F. D. Jole. São Paulo: Edusp/Nev-USP, 2013. pp. 649-655. 